\title{
WRITING PERSONAL LANGUAGE EXPERIENCE: TOWARDS A TASK-BASED METACOGNITIVE AND SELF-REFLEXIVE PRACTICE IN UG LEARNERS
}

\begin{abstract}
While it has been established that adult foreign/second language learners benefit from metacognitive awareness about their own learning (Maki and McGuire 2002; Anderson 2002, Livingston 1997, Wenden 1998), many of the prevalent practices in the language syllabi for higher education in India are yet to reflect this fact fully. A learner's awareness about the phases of learning - from planning one's language learning to monitoring and evaluating one's strategies - can lead to improved language skills.

It has been observed that learners want to improve their writing and teachers advise them to practice writing, but learners do not know what they should write about. In this scenario, writing personal journals about language learning experience is considered to be 'a painless way' (Hopkins 2010) to improve writing. Since it involves not only the mechanical process or 'practice' of writing but also reflective thinking, it helps students achieve focus and a better knowledge about their own learning style.

The present paper describes in detail the current approach and practices of including writing tasks on learners' language experience, the objectives, materials, methods for developing/selecting materials, benefits, taskdesigns as well as evaluating strategies for and the outcomes of such inclusions. The paper also discusses the Indian context and differences to be taken into consideration to this basically non-Indian approach. The focus in this paper is primarily on basic expressive writing and secondarily on the transition to the stage of creative writing. It is hoped that this conceptual and descriptive paper will lead to more eclectic designs and practices to verify the efficacy and suitability of the approach.
\end{abstract}

Keywords : Metacognitive awareness, task based approach, Task based language teaching, writing tasks, eclectic designs

\section{INTRODUCTION}

Writing in English for many ELLs is a strenuous task and given a choice, they choose their mother tongue for writing. However, writing being an essential skill, learners cannot stay away from writing if they wish to be proficient in English. Learners are conscious about the importance associated with writing in English, but they find it demanding to use this productive skill of the language. Kanwal and Khurshid (2012) have observed in a study that more students preferred their first language to English. The tendency to use the mother tongue in the language transactions with a choice of language is observed among even the intermediate and advanced ELLs. It is not uncommon to see learners writing first in their native language and then trying to translate the text in English. Some of the common reasons quoted by ELLs for not choosing English for writing are fear of being incorrect in terms of spelling and grammar, fear of sounding foolish, getting conscious about writing, lack of confidence and miscommunication.

There have been many approaches to teach writing in an additional language. In 1940s and 1950s, audiolingual method was popular in writing classrooms. The aim of teaching writing was to reinforce oral language skills. The focus was on grammatical structures and classroom activities included gap-filling, substitutions, transformations 


\section{GAP BODHI TARU - A Global Journal of Humanities}

and controlled composition. Similarly the models approach to writing provided advanced learners with paragraphs that learners could imitate and develop writing by developing an outline structure. After its criticism in 1970s, the models approach was almost replaced by the process approach, which was learner-centred. Instead of the focus on grammatical forms, the focus here was on meaning-making, invention and multiple drafts. Taylor (1976) argued that even low-proficiency students can compose written texts and the emphasis on accuracy could hinder learns' development in terms of writing. In such approaches the process of writing became important, rather than the product. In 1986, to suit the academic demands, content-based approach was adopted. As Snow and Brinton (1988) observe, writing topics were often assigned on the basis of a particular discipline or a course. Concurrently, English for Academic Purposes was introduced where the emphasis was on rhetorical forms.

Lately, however, all these approaches are under a critique and researchers such as Frodesen (2001) and Hinkel (2003) recommend that writing in an additional language should include form as well as meaning. This paper attempts to establish a possibility to improve writing in English (as an additional language) using eclectically the personal language learning experiences as narrated by adult learners in writing. This paper sees language learning narratives of ESL learners as eclectic versions of the LEA and narrative approaches. To ease the output, appropriate writing tasks could be used.

It is with reference to the inhibitions learners experience in writing in English that the Language Experience Approach (LEA) can be employed fruitfully. The Language Experience Approach (LEA) draws upon and takes advantage of this important link between experience and education by using student narratives as the basis for reading instruction. Language Experience Approach is not a new approach as such. Wurr (2002) states that LEA has been a basis for learning and literacy since Dewey and Huey. The LEA, first developed for Maori-speaking (Ashton-Warner, 1963) and native-English-speaking children (Spache \& Spache, 1964; Stauffer, 1965), has also been used successfully with learners of all ages. Adult learners entering ESL programs may or may not have previous educational or literacy experiences; nonetheless, all come to class with a wealth of life experiences. This valuable resource for language and literacy development can be tapped by using the LEA. The approach develops literacy not only with the whole learner in mind, but also the whole language.Although this approach is better associated with literacy in the first language, it was used successfully for second language skills in 1980s and 1990s. In all forms of LEA, the central principle is to use the student's own vocabulary, language patterns, and background of experiences to create reading texts, making reading an especially meaningful and enjoyable process. Dixon and Nessel (1983, pp. ix-x) outline a five-step process :

1. Teacher and student discuss the topic to be focused on in the dictation. Observations and opinions are exchanged. Oral language skills are developed and reinforced.

2. The student dictates an account or story to the teacher, who records the statements to construct the basic reading material.

3. The student reads the story several times (with the teacher helping as needed), until the story has become quite familiar. Reading comprehension is made easier by the fact that the student is reading material that is self-generated.

4. Individual story words are learned, and other reading skills are reinforced through teacher-designed activities related to the story.

5. Students move from reading their own dictation to reading other-author materials as they develop confidence and skill with the reading process.

Jones (1986) associates with these five steps certain key-principles of learning:

1. Learning occurs from the known to the unknown. The learner begins with his or her own spoken language.

2. Learning occurs most effectively in a general to specific direction. In reading, students must be immersed in a meaningful context of written language for learning to be most effective.

3. Struggling adult readers usually have a low self-concept as readers and need to be assured of some immediate success. There is little to lose and much to gain with the LEA and assisted readings.

4. Adult learners are often very time conscious and need to leave each lesson with a feeling of accomplishment. Everyone reads at every LEA session. 


\section{GAP BODHI TARU - A Global Journal of Humanities}

While Dixon, Nessel and Jones have applied much of the LEA to reading, it is possible to adapt this approach for teaching and improving writing. The LEA could be narrowed to language learning experiences of the learners at an advanced stage. Similarly, the narrative approach to language learning, although sometimes dismissed as anecdotal or insufficiently rigorous, has been attracting increasing interest from linguists in recent years because of its potential to provide rich insights into individual experience, thereby shedding light on the process of language learning. When an adult learner narrates in writing his language learning or other experiences, the content is known to her and the learner becomes the narrator. Thus there is a strong identification with the narrator and the content. As in the LEA, narrative writing creates the content and therefore the process of editing and improving sees increased motivation. As adult learners are found to be better metacognitive learners, narrating their own experience of learning makes them conscious of their learning style and patterns. This exercise can unify their thought and expression and vice-versa. Narrative-based intervention wouldyield better outcomes than the standard practice intervention because it provided learners withcontextual cues, redundancy, and predictability, which should promote learning andgeneralization. Narrative writing skills can help students in other forms of writing as well. Ideally, these exercises in narrating personal learning experiences develop BICS (basic interpersonal communication skills) as well as CALP (cognitive academic language proficiency).

In a study carried out in Malaysia (Su Chu 2012:97), learners reported that the most important for their inhibition to write is that they did not have an idea to write. Secondly, the learners wanted repeated readings to see the connection to what they were writing. These two problems are resolved for most learners when they write about their own language learning experience. They will be well-connected to and identify with the subject of their writing. Unlike an abstract situation to which all learners may not identify, here they will recall only what is memorable and important to them. The other to inhibiting factors stated in the same research - the problems of spelling, grammar and expression - could be dealt with during the editing and revision stage, as believed by Zamel (1983).

According to the learners in the above study, the most difficult phase of a writing exercise was the pre-writing make up. To ease this difficulty, one can use a task based approach and divide the tasks in small modules. The above study used the following prewriting strategies as employed by the subjects:

1. Looking at a model essay

2. Thinking about the ideas in L1

3. Making a relevant word list

4. Outline in L1

5. Plan only for the first paragraph

6. Plan the content for each of the paragraphs

The following clues could be thought of to help the learners start writing:

1. Write about your first known exposure to English. Try to recall the memories associated with your first contact with English.

2. Imagine you were observed by a biographer while you were trying to learn English. What incidents your biographer would have chosen to talk about you? Be your own biographer.

3. What do you think were the difficulties you encountered while learning English. What did you do to overcome them?

4. Comment on the factors and levels of motivation for you in learning English.

5. What difficulties do you still face in using English?

6. Think of a time when you felt content after learning something you thought very vital to your understanding of English.

7. What did you try out on your own while learning English? Did someone help you?

8. How did you feel when learning English at first?

9. Did you ever feel like giving up learning English? Why?

One of the other advantages of using learner experience in writing tasks is that the experience will always be better organised compared to writing on anything else. Thus among the rubrics of testing narrative writing, learners will always score better for the organisation part. 


\section{GAP BODHI TARU - A Global Journal of Humanities}

As for testing and evaluating learner experiences, teachers have to consider the fact that these are their personal experiences and what may sound absurd may just be a learner's inability to express or to find the right words. Collaborative revision and oral verification, confirmation, informal discussions and restructuring could help the students well. Peer reviews of the drafts could also be effective. Regular journal entries and positive feedback, minimal ink on the paper and other common strategies work here as well.

\section{Works Cited}

Ashton-Warner, S. (1963). Teacher. New York: Simon \& Schuster.

Dixon, C. N., \& Nessel, D. D. (1983). Language experience approach to reading and writing: Language experience reading for second language learners. Hayward, CA: Alemany Press.

Kanwal, W. and Khurshid, F. (2012). University Students' Difficulties in Learning English Language Skills. Language in India, 12. 327-337.

Snow, M.A. \& Brinton D. (1988). Content-based language instruction: Investigating the effectiveness of the adjunct model. TESOL Quarterly, 22, 553-574.

Spache, G., \& Spache, E. (1964). Reading in the elementary school. New York: Allyn \& Bacon.

Stauffer, R. G. (1965). A language experience approach. In J.A. Kerfoot (Ed.), First grade reading programs, perspectives in reading No. 5. Newark, DE: International Reading Association.

$\mathrm{Su} \mathrm{Chu}, \mathrm{A} . \mathrm{W}$. (2012). An Investigation of the Predictors of L2 Writing among Adult ESL Students. Chirstchurch:Univ.of Canterbury Press.

Taylor, B. (1976). Teaching composition to low-level ESL students. TESOL Quarterly, 10, 309-319.

Wurr, A.J. (2002). Language Experience Approach Revisited : The Use of Personal Narratives in Adult L2 Literacy Instruction. Reading Matrix. Vol 2., No. 1. <http://www.readingmatrix.com/articles/wurr/> DoA: 9 Jan 2015.

Zamel, V. (1983). The composing process of advanced ESL students: Six case studies. TESOL Quarterly, 17, 165184. 